\title{
Strategies of Carious Tissue Removal in Deep Carious Lesions among Dentists in Iraq: Online Based Survey Study
}

\author{
Noor H. Fadhil ${ }^{1}$, Anas F. Mahdee ${ }^{2}$, Ahmed H. Ali $^{3}$ \\ ${ }^{1}$ Assistant Lecturer, ${ }^{2}$ Assistant Professor, ${ }^{3}$ Lecturer, Department of Aesthetic and Restorative Dentistry, \\ College of Dentistry, University of Baghdad, Baghdad, Iraq
}

\begin{abstract}
The aim was to find out the preferences of dentists in Iraq regarding strategies of carious tissue removal in management of deep carious lesions (CR) in asymptomatic teeth and how demographics (sex, years of experience, qualification, specialty, place of work) influences these preferences. An online questionnaire of two months duration was constructed and distributed randomly via social media (Facebook). The questionnaire' questions investigated the demographics, CR (included non-selective removal to hard dentine (NS), stepwise (SW) and selective (SE) removal). 238 dentists participated in the study, 164 (69\%), 56 (23.5\%) and 18 (7.5\%) of respondents prefer NS, SW and SEremoval, respectively. Significantly both GDP and males prefer NS more than Endodontists and females $(\mathrm{P}<0.05)$, Percent of respondents work in private clinics who perform non-selective removal (53.6\%) significantly lower than those who work in hospitals $(73.6 \%)(\mathrm{p}<0.01)$. less invasive CR significantly associated with being an endodontist or female or work in a private clinic $(\mathrm{OR}=2.02$, CI 95\% 1.02-4.0), $(\mathrm{OR}=2.04$, CI 95\% 1.12-3.7) and (OR=2.1, CI 95\% 1.0-4.0), respectively. In conclusion Iraqi GDPs prefer invasive strategy of carious tissue removal in management of deep carious lesions. Specialty, place of work and sex of respondents affected these choices significantly.
\end{abstract}

Keywords: Selective, stepwise, deep carious lesion, dentists, attitude.

\section{Introduction}

The treatment of deep dentin caries is a daily practice for most dentists worldwide. However, there is no consensus in the dental profession regarding the best practice protocol, excavation technique, treatment option in the event of pulp exposure or suitable materials after pulp exposure. Traditionally removal of all heavily contaminated and demineralized dentin in deep carious lesions (non-selective carious tissue removal to hard dentine) was the aim of dentists in the case of treatment of deep carious lesion ${ }^{1}$, this procedure may result in a pulpal exposure often. Therefore, attention has brought

\section{Corresponding Author:}

\section{Dr. Ahmed H. Ali}

Lecturer, Department of Aesthetic and Restorative

Dentistry, College of Dentistry, University of Baghdad.

Dental Educational Hospital, Baghdad, Iraq

e-mail: ahmedhamidalisalman@gmail.com

Mob.: 99647713115902 to a more minimal invasive method such as stepwise removal and selective removal (to leathery dentin), which shows higher success rates and lower risk of pulp exposure compared to non-selective removal to hard dentine $^{2,3}$. In these removal techniques, all peripheral carious dentine is removed leaving some carious tissue over the pulp wall before permanent restoration in case of selective removal at the same visit ${ }^{4}$, but re-entry is needed in stepwise removal to remove the remaining soft dentine before permanent restoration after temporarily sealing period. Higher success rate of the selective removal compared to stepwise removal reported, suggesting no need for re-entry ${ }^{3,5}$.

There is no existing data regarding how dental professionals manage deep carious lesions in Iraq, the aim of this study was to investigate the preference of strategies of carious tissue removal in management of deep carious lesions by the dental practitioners in Iraq and how the respondents' demographic variables (sex, years of experience, qualification, specialty, place of work) influences these decisions. 


\section{Materials and Method}

An online questionnaire was designed and piloted through staff members at College of Dentistry/University of Baghdad. A sample size calculation was carried out through population for descriptive sampling technique with an expected response rate between 60 and 80 and $80 \%$ power calculation. Hence, 350 dentists were needed to respond. Online questionnaire was constructed using Google form, A section of the questionnaire constructed as a cover letter explaining the purpose of the questionnaire and emphasis on anonymity. The questionnaire questions investigated:

1. Demographics of respondent which included: sex, years of experience, qualification (BDS, Diploma, $\mathrm{MSc}$ and $\mathrm{PhD}$ ), specialty (Endodontists, general dental practitioner (GDP) and other specialty (referred to as "other")), place of work (private clinic or hospital).

2. Carious tissue removal technique (non-selective vs stepwise vs selective removal) in deep carious lesions in asymptomatic teeth.

The questionnaire was sent electronically via social media (Facebook) with respondents completing the form anonymously. The distribution was performed through mailing to members of certain Iraqi Dental Facebook groups which were assigned using a simple randomization-lottery method to minimize bias in selection. The issue with respondents making more than one entry was excluded by using an IP-protection protocol. The respondents were asked to choose one suitable answer for each question. Ethical approval was considered unnecessary as there was no patient information included, only dentists were asked about their preference. Responses in the Google form gathered as Excel sheet. The collected data was analyzed using the statistical package SPSS 26 (SPSS Inc., Chicago, IL, USA). Descriptive statistics given as frequencies (n) and percent (\%). Chi Square test was used to investigate the influence of gender, qualification, specialty, place of work and years of experience on the choice of carious tissue removal strategy and treatment option after pulp exposure. The background characteristic variable was chosen as an independent variable for the binary multivariable logistic regression analysis. Through this, odds ratios (OR) and their confidence intervals (CI) were calculated

\section{Results}

Demographic Data: 238 dentists responded in the study. Table 1 shows the demographic characteristics of the respondents in the study.

\section{Table 1: Demographic characteristics of the respondents in the study.}

\begin{tabular}{|l|c|}
\hline Categories & n (\%) \\
\hline Sex: & $100(42 \%)$ \\
a. Females & $138(58 \%)$ \\
b. Males & \\
\hline Experience: & $80(33.6 \%)$ \\
a. Less than 5 years & $52(21.8 \%)$ \\
b. 5-10 years & $62(26 \%)$ \\
c. $10-20$ years & $44(18.4 \%)$ \\
d. More than 20 years & \\
\hline Qualifications: & $136(57 \%)$ \\
a. BDS & $17(7 \%)$ \\
b. DIPLOMA & $52(22 \%)$ \\
c. MSc & $33(14 \%)$ \\
d. PhD & \\
\hline Specialty: & $116(48.7 \%)$ \\
a. General practitioner & $58(24.4 \%)$ \\
b. Endodontists & $64(26.9 \%)$ \\
c. Other specialties & \\
\hline Place of work: & $56(23 \%)$ \\
a. Private clinic & $183(27 \%)$ \\
b. Hospital &
\end{tabular}

$\mathrm{n}(\%)=$ number (percentage) of respondents

\section{Strategy of carious tissue removal in management} of deep carious lesion in asymptomatic teeth:

$164(69 \%), 56(23.5 \%)$ and $18(7.5 \%)$ of respondents choose to use non-selective, stepwise and selective carious tissue excavation in treatment deep carious lesions, respectively, with statistically significant difference between frequencies $(p<0.001)$. Years of experience, age, qualification did not statistically significantly affect the decision of selection of the strategy used to remove carious tissue in deep carious lesions.

Specialty significantly affects the decision of carious tissue removal technique $(p=0.05)$. Percent of endodontists who perform non-selective removal (55.2\%) significantly lower than those in GDP (72.4\%) $(p<0.05)$ and Other $(75 \%) \quad(p<0.05)$, respectively. 
Significantly higher percent of Endodontists perform stepwise removal compared to GDP $(p<0.05)$ and Other $(\mathrm{P}<0.01)$, respectively. No differences in percentages of respondents who perform selective removal in all categories $(\mathrm{p}>0.05)$.

Sex significantly affect the decision of carious tissue removal technique $(\mathrm{p}=0.026)$. Significantly more males (75.4\%) use non-selective removal compared to females $(60 \%)(p<0.05)$. Significantly more females $(32 \%)$ use stepwise removal compared to males $(17.4 \%)(p<0.01)$. There was no significant difference in percentages of respondents who perform selective removal in different $\operatorname{sex}(p>0.05)$.
Place of work significantly affects the decision of carious tissue removal technique $(\mathrm{p}=0.018)$. Percent of respondents work in private clinics who perform nonselective removal (53.6\%) significantly lower than those who work in hospitals $(73.6 \%)(p<0.01)$. Percent of respondents work in private clinics who perform stepwise removal (35.7\%) significantly higher than those who work in hospitals $(19.7 \%)(\mathrm{p}<0.05)$. There was no significant difference in percentages of respondents who perform selective removal in private clinics $(10.7 \%)$ and hospitals (6.5\%) $(\mathrm{P}>0.05)$, as shown in Table 2 .

Table 2: Distribution of frequencies and percentages of Strategy of Carious tissue removal among significant demographic categories.

\begin{tabular}{|l|c|c|c|c|}
\hline \multirow{2}{*}{$\begin{array}{l}\text { Respondents } \\
\text { Categories }\end{array}$} & Strategy of Carious Tissue removal n (\%) \\
\cline { 2 - 4 } Specialty n (\%) & Stepwise removal & Selective removal & Total \\
\hline Endodontists & $32(55.2 \%)^{\mathrm{a}}$ & $22(37.9 \%)^{\mathrm{b}}$ & $4(6.9 \%)$ & $58(24.3 \%)$ \\
Others & $48(75 \%)^{\mathrm{a}}$ & $12(18.8 \%)^{\mathrm{b}}$ & $4(6.3 \%)$ & $64(26.8 \%)$ \\
GDP & $84(72.4 \%)^{\mathrm{a}}$ & $22(19 \%)^{\mathrm{b}}$ & $10(8.6 \%)$ & $116(48.7 \%)$ \\
Total & $\mathbf{1 6 4 ( 6 9 \% )}$ & $\mathbf{5 6 ( 2 3 . 5 \% )}$ & $\mathbf{1 8 ( 7 . 5 \% )}$ & $\mathbf{2 3 8 ( 1 0 0 \% )}$ \\
\hline Sex n (\%) & \multicolumn{5}{|c|}{} \\
\hline Females & $60(60 \%)^{\mathrm{c}}$ & $32(32 \%)^{\mathrm{d}}$ & $8(8 \%)$ & $100(42 \%)$ \\
Males & $104(75.4 \%)^{\mathrm{c}}$ & $24(17.4 \%)^{\mathrm{d}}$ & $10(7.2 \%)$ & $138(58 \%)$ \\
Total & $\mathbf{1 6 4 ( 6 9 \% )}$ & $\mathbf{5 6 ( 2 3 . 5 \% )}$ & $\mathbf{1 8 ( 7 . 5 \% )}$ & $\mathbf{2 3 8 ( 1 0 0 \% )}$ \\
\hline Place of Work n (\%) & \multicolumn{5}{|c|}{} \\
\hline Private clinics & $30(53.6 \%)^{\mathrm{e}}$ & $20(35.7 \%)^{\mathrm{f}}$ & $6(10.7 \%)$ & $56(23.5 \%)$ \\
Hospitals & $134(73.2 \%)^{\mathrm{e}}$ & $36(19.7 \%)^{\mathrm{f}}$ & $12(6.5 \%)$ & $182(76.5 \%)$ \\
Total & $\mathbf{1 6 4 ( 6 9 \% )}$ & $\mathbf{5 6 ( 2 3 . 5 \% )}$ & $\mathbf{1 8 ( 7 . 5 \% )}$ & $\mathbf{2 3 8 ( 1 0 0 \% )}$ \\
\hline
\end{tabular}

$\mathrm{n}=$ number of respondents, identical superscript small letters represent statistically significant difference among the relevant groups.

For the purpose of statistical analysis via binary multivariable logistic regression, CR categories classified into invasive (non-selective removal) and less invasive (include stepwise and selective caries removal). Results of regression analysis show that being an endodontist or female or work in a private clinic significantly associated with choosing a less invasive carious tissue removal strategy (stepwise or selective removal) in management of deep carious lesions $(\mathrm{OR}=2.023, \mathrm{CI}$ 1.02-4.0), $(\mathrm{OR}=2.044, \mathrm{CI} 1.12-3.7)$ and $(\mathrm{OR}=2.101$, CI $1.0-4.0)$, respectively.

\section{Discussion}

With development of minimal invasive approaches in the management of deep carious lesions, it is important to investigate existing dentists' attitude and preferences toward these approaches and to assess the effect of different demographic factors influencing these choices. Therefore, this study is the first to compare and analyses management of deep carious lesions in Iraq. In this study, social media platforms were used to distribute the questionnaire into targeted groups representing the dentist population in Iraq. Rapid and effective sharing of information allowed by social media widely used by the population ${ }^{6}$. Daily, there are 1.52 billion active users of Facebook alone and 2.7 billion subscribers use social 
media ${ }^{7}$. This media has been suggested as an alternative way for communications in a survey study involving medical professionals to assess social media use with a response rate of $64 \%{ }^{7}$. This study showed a response rate of $68 \%$ which is satisfactory and representing the targeted population.

Majority of dentists who surveyed in this study (69\%) preferred a non-selective carious tissue removal strategy in management of asymptomatic deep carious lesions and refused to leave caries under restoration. This decision is related to the idea that residual caries might progress and harm the pulp. According to the results, less invasive excavation method (stepwise and selective excavation) were chosen by $31 \%$ of the respondents, this result is in agreement with studies in United States and Brazil, reporting that only $21 \%{ }^{8}$ and $26 \%{ }^{9}$ of dentists considered incomplete excavation of pulp-proximal caries. Other studies carried out in USA, France, Germany and Brazil showed that majority of dentists (60-70\%) preferred non-selective carious tissue removal to the hard dentine in management of deep carious lesions even with high risk of pulp exposure during the excavation procedure ${ }^{8-10}$, similar to the results of this study.

Reduced risk of pulp exposure and pulpal complications associated with in complete excavation (selective removal) versus complete excavation (nonselective removal to hard dentine) has been confirmed recently by reviews and meta-analysis 10,11 . Although the idea of leaving residual caries in proximity to the pulp bears the fear of restoration failure, failure risk did not seem to be increased significantly $(\mathrm{OR}=0.97$, 95\% CI $=0.64-1.46)$. Therefore, current scientific evidence supports selective removal of caries if the residual carious lesion is sealed successfully with no indication for a considerable risk of progress ${ }^{12,13}$. Also, recent randomized clinical trial supports the advantage of selective removal of carious tissue in deep carious lesion with symptoms of reversible pulpitis using a selflimiting excavation protocol (Carisolv gel and operating microscope) which maintain $90 \%$ pulp survival rate after one year of follow-up utilizing CBCT for radiographic evaluation of periapical health ${ }^{4}$. However long-term follow-up of teeth excavated selectively is limited.

One of the factors that affected preference of carious tissue removal strategy was specialty of the respondent, half of Endodontists prefer less invasive CR compared to GDP and other specialties significantly (Table 2), being an Endodontist increased the probability of choosing less invasive method by 2 times compared to GDPs (OR=2.023, CI (95\%)1.02-4.0). This could be explained by the fact that endodontists may become more conscious about the recent clinical guidelines that outline the benefits of less invasive carious tissue removal strategies ${ }^{11,14-16 .}$

Also, results of this study show that females prefer a less invasive approach in caries excavation of deep carious lesions (Table 2). The preference of a less invasive carious tissue removal strategy was significantly associated with the gender "female" $(\mathrm{OR}=2.044, \mathrm{CI}$ $(95 \%) 1.12-3.7)$. This agrees with another multi-national survey study which found that stepwise removal was performed less often by male dentists ${ }^{10}$. However other studies could not find such association between gender and CR strategy preference ${ }^{17,18}$.

Result of this study found that place of work significantly affects the decision of carious tissue removal technique. work in private clinics strongly associated with choosing less invasive $\mathrm{Cr}$ compared to working in hospitals Table 2. This disagrees with results from other studies which found a strong correlation between employment in the public sector and choosing a less invasive strategy 10,18 . This probably can be explained by lack of local clinical guidelines that promote less invasive carious tissue removal strategies in the public sector compared to the private sector in Iraq which have more diversity and flexibility in terms of time and financial consideration. Also, it seems that treatment decision guided by previous experience and familiarities, for example, dental Under and postgraduate education significantly affect the dentist decision regarding the strategy of carious tissue removal adopted, most Iraqi dental schools teaches the contemporary invasive approach of non-selective carious tissue removal to hard dentine.

In conclusion, majority of the surveyed dentists preferred invasive carious tissue removal strategies in excavation of asymptomatic deep carious lesions. Therefore, benefits of selective excavation should be highlighted in under- and postgraduate education to promote minimally invasive techniques. Less invasive strategies in management of deep carious lesions and vital pulp therapies are not common in clinical practice in Iraq and there is urgent need to educate GDPs the current scientific evidence on less invasive strategies. 


\section{Conflict of Interest: Nil}

Source of Funding: Self-funded

Ethical Clearance: Not Required

\section{References}

1. Innes N, Frencken JE, Bjørndal L, Maltz M, Manton DJ, Ricketts D, et al. Managing carious lesions: consensus recommendations on terminology. Advances in dental research. 2016;28(2):49-57.

2. Bjørndal L, Reit C, Bruun G, Markvart M, Kjældgaard M, Näsman P, et al. Treatment of deep caries lesions in adults: randomized clinical trials comparing stepwise vs. direct complete excavation, and direct pulp capping vs. partial pulpotomy. European journal of oral sciences. 2010;118(3):290-7.

3. Maltz M, Garcia R, Jardim JJ, de Paula LM, Yamaguti PM, Moura MS, et al. Randomized trial of partial vs. stepwise caries removal: 3-year follow-up. J Dent Res. 2012;91(11):1026-31.

4. Ali A, Koller G, Foschi F, Andiappan M, Bruce K, Banerjee A, et al. Self-limiting versus conventional caries removal: a randomized clinical trial. Journal of dental research. 2018;97(11):1207-13.

5. Carvalho JC, Dige I, Machiulskiene V, Qvist V, Bakhshandeh A, Fatturi-Parolo C, et al. Occlusal caries: biological approach for its diagnosis and management. Caries Research. 2016;50(6):527-42.

6. Boyd DM, Ellison NB. Social network sites: Definition, history, and scholarship. Journal of computer-mediated communication. 2007; 13(1):210-30.

7. Petosic A, Sunde K, Beeckman D, Flaatten HK, Wøien $\mathrm{H}$. Use of social media for communicating about critical care topics: A Norwegian crosssectional survey. Acta Anaesthesiologica Scandinavica. 2019;63(10):1398-405.

8. Oen KT, Thompson VP, Vena D, Caufield PW, Curro F, Dasanayake A, et al. Attitudes and expectations of treating deep caries: a PEARL Network survey. General dentistry. 2007;55(3):197-203.

9. Weber CM, Alves LS, Maltz M. Treatment decisions for deep carious lesions in the Public
Health Service in Southern Brazil. Journal of public health dentistry. 2011;71(4):265-70.

10. Schwendicke F, Stangvaltaite L, Holmgren C, Maltz M, Finet M, Elhennawy K, et al. Dentists' attitudes and behaviour regarding deep carious lesion management: a multi-national survey. Clinical oral investigations. 2017;21(1):191-8.

11. Ricketts D, Lamont T, Innes NP, Kidd E, Clarkson JE. Operative caries management in adults and children. Cochrane database of systematic reviews. 2013(3).

12. Bjørndal L, Larsen T, Thylstrup A. A clinical and microbiological study of deep carious lesions during stepwise excavation using long treatment intervals. Caries Research. 1997;31(6):411-7.

13. Maltz M, de Oliveira EF, Fontanella V, Bianchi R. A clinical, microbiologic, and radiographic study of deep caries lesions after incomplete caries removal. Quintessence international. 2002;33(2).

14. Schwendicke F, Dörfer C, Paris S. Incomplete caries removal: a systematic review and meta-analysis. Journal of dental research. 2013;92(4):306-14.

15. Endodontology: ESo, Duncan H, Galler K, Tomson P, Simon S, El-Karim I, et al. European Society of Endodontology position statement: Management of deep caries and the exposed pulp. International endodontic journal. 2019;52(7):923-34.

16. Bjørndal L, Simon S, Tomson P, Duncan H. Management of deep caries and the exposed pulp. International endodontic journal. 2019;52(7):94973.

17. Stangvaltaite L, Kundzina R, Eriksen HM, Kerosuo E. Treatment preferences of deep carious lesions in mature teeth: questionnaire study among dentists in Northern Norway. Acta Odontologica Scandinavica. 2013;71(6):1532-7.

18. Croft K, Kervanto-Seppälä S, Stangvaltaite L, Kerosuo E. Management of deep carious lesions and pulps exposed during carious tissue removal in adults: a questionnaire study among dentists in Finland. Clinical oral investigations. 2019;23(3):1271-80. 